\title{
Invasive meningococcal disease in older adults in North America and Europe: is this the time for action? A review of the literature
}

Sandra Guedes ${ }^{1}$, Isabelle Bertrand-Gerentes ${ }^{1}$, Keith Evans ${ }^{2}$, Florence Coste ${ }^{1}$ and Philipp Oster ${ }^{1 *}$

\begin{abstract}
Background: Neisseria meningitidis is an encapsulated Gram-negative diplococcus that asymptomatically colonises the upper respiratory tract in up to $25 \%$ of the population (mainly adolescents and young adults). Invasive meningococcal disease (IMD) caused by Neisseria meningitidis imposes a substantial public health burden,. The case fatality rate (CFR) of IMD remains high. IMD epidemiology varies markedly by region and over time, and there appears to be a shift in the epidemiology towards older adults. The objective of our review was to assess the published data on the epidemiology of IMD in older adults (those aged $\geq 55$ years)in North America and Europe. Such information would assist decision-makers at national and international levels in developing future public health programmes for managing IMD.
\end{abstract}

Methods: A comprehensive literature review was undertaken on 11 August 2020 across three databases: EMBASE, Medline and BIOSIS. Papers were included if they met the following criteria: full paper written in the English language; included patients aged $\geq 56$ years; were published between 1/1/2009 11/9/2020 and included patients with either suspected or confirmed IMD or infection with N. meningitidis in North America or Europe. Case studies/reports/series were eligible for inclusion if they included persons in the age range of interest. Animal studies and letters to editors were excluded. In addition, the websites of international and national organisations and societies were also checked for relevant information.

Results: There were 5,364 citations identified in total, of which 76 publications were included in this review. We identified that older adults with IMD were mainly affected by serogroups $W$ and $Y$, which are generally not the predominant strains in circulation in most countries. Older adults had the highest CFRs, probably linked to underlying comorbidities and more atypical presentations hindering appropriate timely management. In addition, there was some evidence of a shift in the incidence of IMD from younger to older adults.

Conclusions: The use of meningococcal vaccines that include coverage against serogroups $W$ and $Y$ in immunization programs for older adults needs to be evaluated to inform health authorities' decisions of the relative benefits of vaccination and the utility of expanding national immunization programmes to this age group.

Keywords: Atypical Presentation, Clinical Burden, Epidemiology, Invasive Meningococcal Disease, Neisseria meningitidis, Older Adults, Recommendations, Serology

*Correspondence: Philipp.Oster@sanofi.com

1 Sanofi Pasteur, 14 Espace Henry Vallée, 69007 Lyon, France

Full list of author information is available at the end of the article

\section{Background}

Neisseria meningitidis is an encapsulated Gram-negative diplococcus that asymptomatically colonises the upper respiratory tract in up to $25 \%$ of the population (mainly 
adolescents and young adults). Twelve different serogroups cause invasive meningococcal disease (IMD)[1] of which six serogroups (A, B, C, W, X, and $\mathrm{Y}$ ) are responsible for most infections [2]. Neisseria meningitidis is one of the leading causes of bacterial meningitis and sepsis globally [3]; less common presentations include pneumonia and a number of other manifestations $[3,4]$. The case fatality rate of meningococcal disease remains high (5-15\%) despite treatment [5-7] and survivors can have significant sequelae, with around $20 \%$ suffering longterm disability [8]. IMD causes a substantial financial burden, often associated with hospitalisation or ongoing treatment of long-term sequaelae [9-15], as well as negatively impacting the quality of life of patients, their families, caregivers and their extended networks $[16,17]$.

Vaccination remains the best strategy to prevent IMD [2], and antibiotics are recommended for post-exposure prophylaxis and treatment [18]. IMD is easily misdiagnosed [18-20], because the severity of illness is often obscured by non-specific symptoms [21], and presentation is similar to that of many self-limiting viral infections [22], or there are extra-meningeal foci of infections, including pneumonia, pericarditis, epiglotitis and conjunctivitis [23-25]. There is also a lack of confirmatory testing available in many healthcare settings. Although first-line antibiotics such as third generation cepholosporins are still effective in the treatment of IMD, the emergence of antibiotic-resistant strains have made IMD management more complex. As a result, morbidity and mortality rates have essentially remained unchanged over the last two decades [24, 26-29].

The epidemiology of IMD varies markedly by region and over time but there are an estimated 500,000 newly diagnosed cases per annum [30]. The highest incidences of IMD are found in countries in the African 'meningitis belt' region, with the lowest incidences found in parts of Europe and the Americas [3]. A recent systematic review showed that serogroup B was responsible for the highest proportion of $N$. meningitidis IMD cases worldwide; nevertheless, the predominant serogroup varies by region, country, age group and over time [31]. Vaccination against IMD has also contributed to the shift in the predominant serogroups. For example, data from Italy [32], Canada [33] and Germany [34] showed that following the introduction of paediatric meningococcal $C$ vaccination, serogroup $C$ cases in children declined, whilst the median age of those affected by serogroup $\mathrm{C}$ increased. For example, in Canada, the median age of cases increased from 16 years in 2003 to 42 years in 2006 [33]. There was also an increased proportion of IMD cases caused by serogroup Y (Germany and Canada) [33, 34] and serogroup B and $Y$ (Italy) [32]. Studies in Australia have also suggested that following the introduction of childhood vaccination against serogroup $C$, the proportion of notified cases in those aged $>65$ years increased [35], whilst studies in the European Union (EU)/European Economic Area (EEA) [36] and Italy [37] also suggested that cases in older adults have increased. Taken together, this would suggest a need to utilise multivalent vaccines and increase vaccine coverage beyond paediatric age groups to counteract these trends.

These epidemiological shifts to older adults have also highlighted the need for further investigation and extension of active surveillance systems (e.g. to include a broader age population than those who are currently covered by national immunisation programs) to accurately assess the changing epidemiology of IMD, and to inform priorities for national health care systems and any associated future vaccination programmes [36-39]. There is an acknowledgement that such data are currently lacking [40].

To date, limited attention has been given to older adults. As such, there is a lack of awareness of the disease in this age group among healthcare professionals, and older adults are not generally considered for immunisation against meningitis. The objective of our review was to assess the published data on the epidemiology of IMD in older adults (generally those aged $\geq 56$ years) in North America and Europe to examine how this has changed over time, the impact it has had in terms of clinical burden and mortality, and the extent of currently available data. Such information would assist recommending bodies at national and international levels in developing future public health programmes for preventing IMD.

\section{Methods}

A search was undertaken on 11 August 2020 across three databases: EMBASE, Medline and BIOSIS. The search used MeSH, EMTREE and free text terms as applicable to the databases. Citations were limited to those in English language, in human subjects and published since 1 January 2009. A simplified version of the search strategy is shown in Supplementary Table S1. Papers were included if they met the following criteria: full paper written in the English language (not just the abstract); included patients aged $\geq 56$ years; was published after 1 January 2009 but before 11 August 2020; and included patients with either suspected or confirmed IMD or infection with $N$. meningitidis in North America or Europe. Case studies/reports/ series were eligible for inclusion if they included persons in the age range of interest. Animal studies, non-English language articles and letters to editors were excluded. Review papers were checked to see if they reported primary data or included studies not captured by the database searches, in which case the original papers were ordered and considered for inclusion. 
Three authors (KE, SG and PO) assessed the studies independently and discussed any papers for which there were disagreements as to their potential inclusion or exclusion. Data from studies which met the inclusion criteria were then entered into Microsoft Excel. Because the potential studies did not involve standardised study designs and the interventions and comparators were not relevant, only participant data and outcomes data were entered. Because the studies covered a wide range of countries and time periods and used various different methods to determine levels of IMD infection, it was felt that any attempt to combine studies in a formal metaanalysis would not be appropriate; therefore, the data extracted from the studies are discussed in a narrative format.

Additionally, the websites of the following international and national organisations and societies were also searched for relevant data on IMD in the age groups of interest: World Health Organization (WHO); European Centre for Disease Prevention and Control (ECDC); US Centers for Disease Control and Prevention (CDC); Active Bacterial Core Surveillance (ABCs); Emerging Infections Program Network; MenAfriNet; National Foundation for Infectious Diseases; Health Protection Scotland (HPS); Public Health England (PHE); National
Institute for Health and Care Excellence (NICE); Institut Pasteur; Robert Koch Institut; Meningitis Research Foundation (MRF) \& Meningitis Progress Tracker; Confederation of Meningitis Organisations (CoMO); Meningitis Now; Global Meningitis Genome Library; Infectious Diseases Society of America (IDSA); European Society of Clinical Microbiology and Infectious Diseases (ESCMID); International Society for Infectious Diseases (ISID); American Society for Microbiology (ASM); and European Society for Paediatric Infectious Diseases (ESPID).

\section{Results}

There were 5,351 citations identified. Following initial review, 505 papers (9\% of the original search) plus 13 identified by searching the reference lists of these papers were obtained for full assessment. Following discussion among the authors, a total of 76 papers were included in this review. The reasons for exclusion are summarized in Fig. 1. Data extracted from each study/website was categorised within three headings, as containing data on epidemiology, atypical presentation or clinical burden of IMD (some contained data in multiple categories). Summary information on the published studies included (not including data taken from websites) can be found in

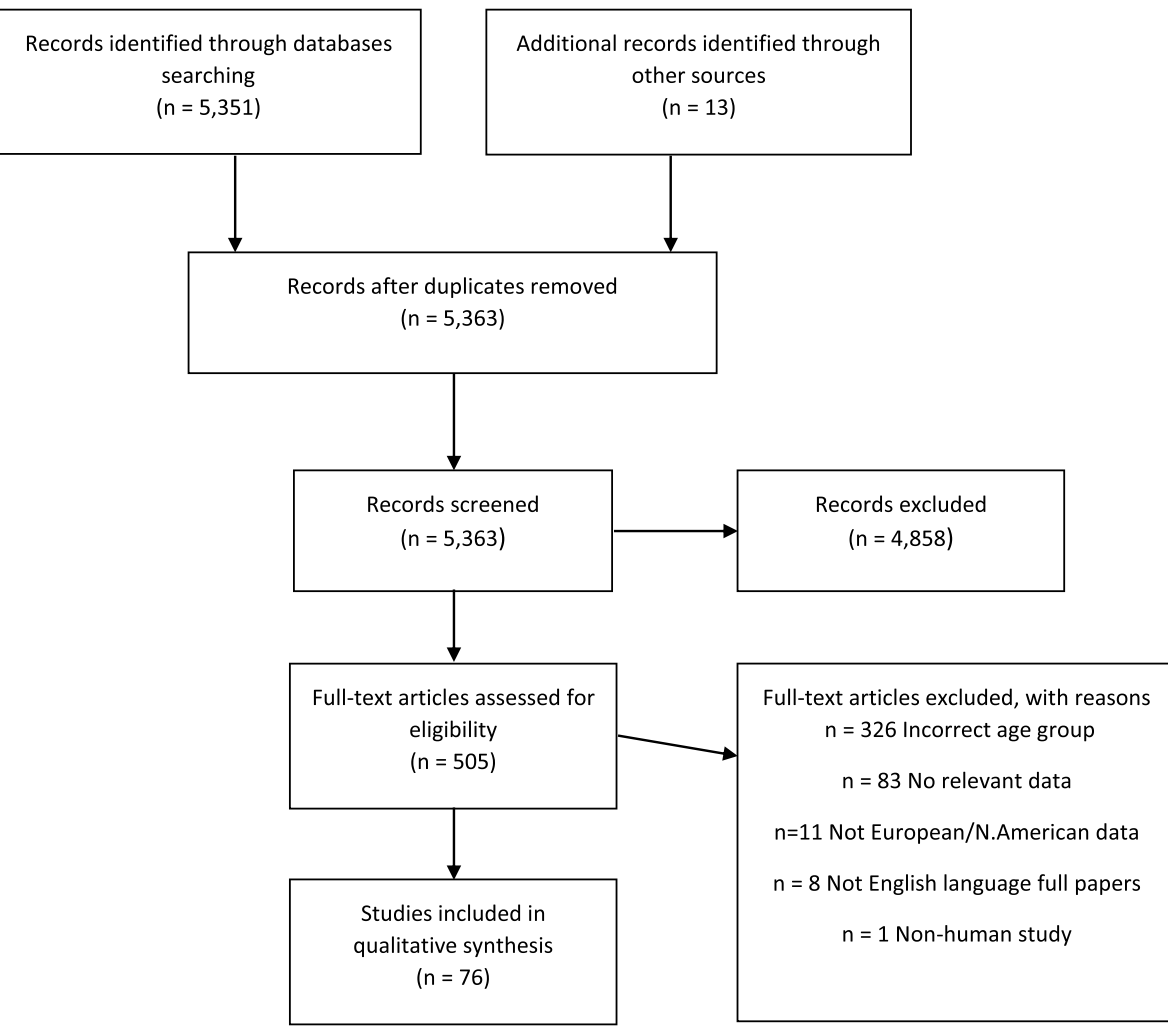

Fig. 1 PRISMA Flow Diagram 
Table 1. Publications we identified, which reported data from national or international organisations (e.g. CDC or ECDC), were not included in Table 1 if the organisation's website provided more recent data which we have then presented below.

\section{Epidemiology Incidence \& Prevalence}

A number of studies/websites showed that, over time, an increasing proportion of IMD cases were in older adults, which may in part be because of improvements in surveillance programmes and as a consequence of meningitis vaccination campaigns focusing almost exclusively on infants and adolescents. The Meningitis Progress Tracker [83] estimated that the global number of IMD cases had slowly increased in the period 2000-2017 (the latest year reported) in those aged 25-64 years (from 61,760 in 2000 to 72,430 in 2017) but remained relatively stable in those aged $\geq 65$ years (from 2,469 in 2000 to 2,422 in 2017). According to recent estimates published as part of the Global Burden of Disease Study [41], the death rate, years of living with a disability (YLD) rate and incidence all increased in the oldest age groups, with meningococcal meningitis and 'other' meningitis causing most of the burden in those aged $\geq 80$ years. It should be noted that both the Meningitis Progress Tracker and the Global Burden of Disease Study take estimates from the same sources available via the Institute of Health Metrics and Evaluation (IHME).

Data from Europe, available on the ECDC website for IMD [84], showed that whilst the overall numbers of confirmed IMD cases decreased in the EU/EEA area since 1999 , the proportion of cases in those aged $>50$ years rose markedly from just under $9 \%$ in 1999 to $32 \%$ in 2018 (the last year for which data are available). This may reflect the success of the meningococcal vaccination program which focused largely on the youngest age groups, shifting the relative burden to older age groups. Studies from several European countries including the UK [42], Finland [85], Italy [43] and Sweden [44] have confirmed the shift in distribution of IMD cases towards older age groups. For example, Stefanelli et al. showed that $52 \%$ of the IMD cases occurred among patients aged $\geq 45$ years since 2013 [43].

Data from the US CDC [86] for 2018 showed that the IMD incidence rates rose with increasing age from 0.16 per 100,000 in those aged $55-59$ years to 0.49 per 100,000 in those aged $\geq 85$ years, and those aged $>45$ years accounted for $47 \%$ (153/329) of confirmed and probable IMD cases reported that year. Of note, only a single US study of men who have sex with men (MSM) was found despite this being a high-risk group for meningococcal disease [45]. Among 74 cases among MSM (0.56 per
$100,000)$ reported to the National Notifiable Disease Surveillance System between January 2012 and June 2015, only a single case was in the older adult age group (5664 years) $(0.008$ per 100,000$)$.

\section{Serogroups}

There were multiple studies/websites that showed infections caused by serogroups $\mathrm{W}$ and $\mathrm{Y}$ were more common in older adults than in young children and adolescents. According to data from the ECDC [84], the most prevalent serogroup in Europe during the period 1999-2018 was serogroup B (51\% of cases and the dominant serogroup in all age groups below 65 years), with serogroups $\mathrm{W}$ and $\mathrm{Y}$ increasingly more prevalent in older adults over time. This may reflect the impact of serogroup $C$ vaccinations over this period in teenagers and young adults, with some of the older adults benefitting from 'herd protection'. A three-fold increase in the incidence of IMD caused by serogroup W was observed between 2013 and 2017, primarily because of increased cases in children aged $<5$ years and adults aged $\geq 50$ years. This increase in the incidence of IMD caused by serogroup $\mathrm{W}$ was confirmed by national institutions such as the Institut Pasteur [87] and many studies in European countries including those from the UK [42, 46, 47], Spain [48], Italy [49], the Netherlands [50, 51], and Sweden [44, 52]. One study in Ireland found serogroup $\mathrm{Y}$ as the predominant strain in those aged $\geq 65$ years [53]. However, another from the Netherlands reported serogroup B as the most prevalent in older adults rather than serogroups $\mathrm{W}$ and Y [54].

Data from the CDC [86] showed that serogroup B was the dominant serogroup in the USA in those aged under 23 years, and serogroups $\mathrm{A}, \mathrm{C}, \mathrm{W}$ and $\mathrm{Y}$ were the dominant serogroups in adults and older adults (0.07 per 100,000 and 0.15 per 100,000 in those aged $25-64$ years and $\geq 65$ years, respectively, compared with 0.03 per 100,000 serogroup B infections in those aged 25-64 years). Latest surveillance data from the ABCs program network that included 10 states reported in 2018 that serogroup $\mathrm{Y}$ was more common in adults (aged $>35$ years) than in younger adults, in whom serogroups $B$ and $C$ were more frequent [88]. Several US studies also found serogroup $\mathrm{Y}$ to be more common in older adults [55-57], for example, Peruski et al. [56] noted that throughout the period 1988 to 2011, serogroup $\mathrm{Y}$ became an increasingly predominant cause of IMD in those aged $\geq 60$ years, accounting for over $50 \%$ of all serogroups isolated in this age group after 1995 . One possible explanation for this apparent increase in serogroup $\mathrm{Y}$ is that many of the cases in this age group were pneumonia with or without bacteraemia, and the latter are generally not considered to be cases of IMD. 


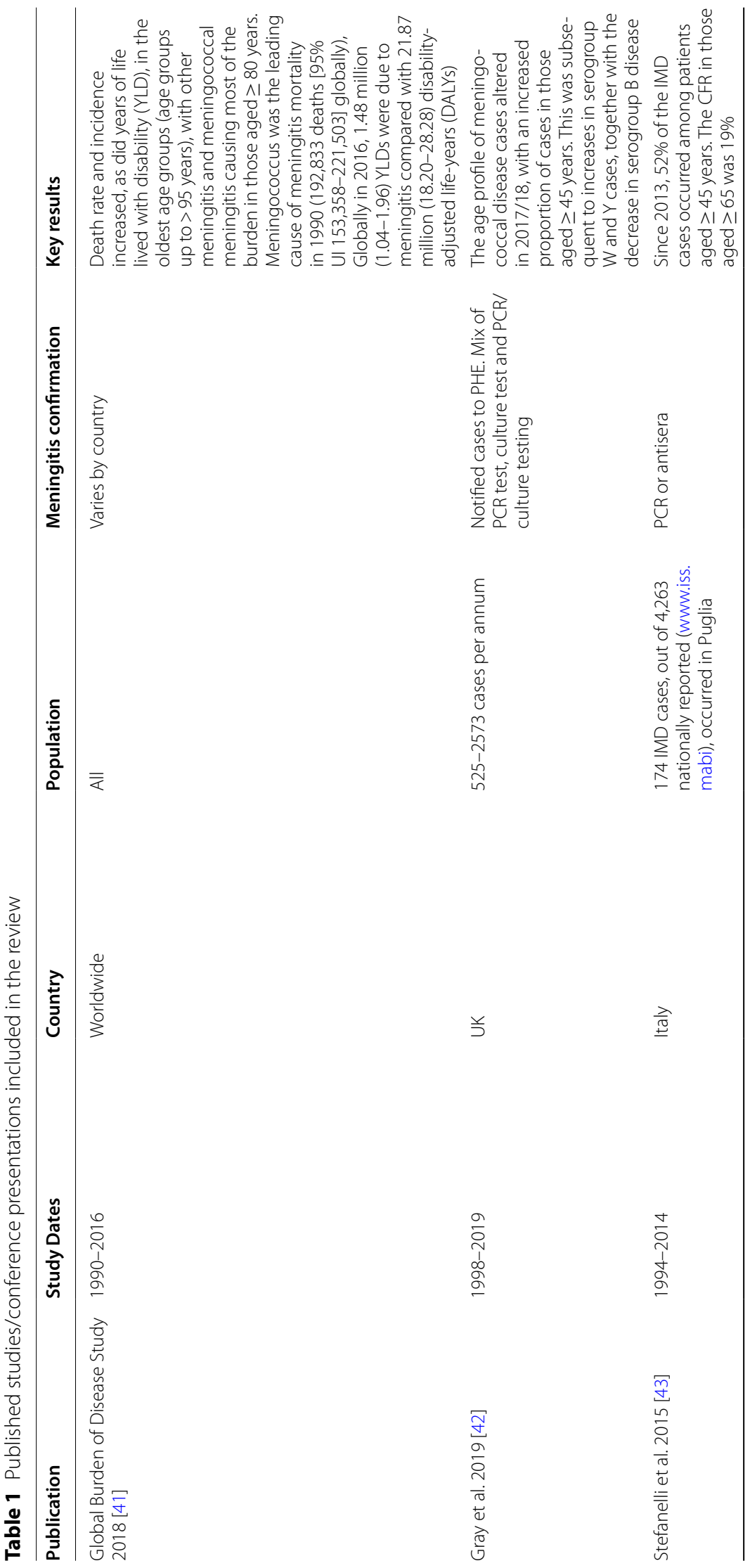




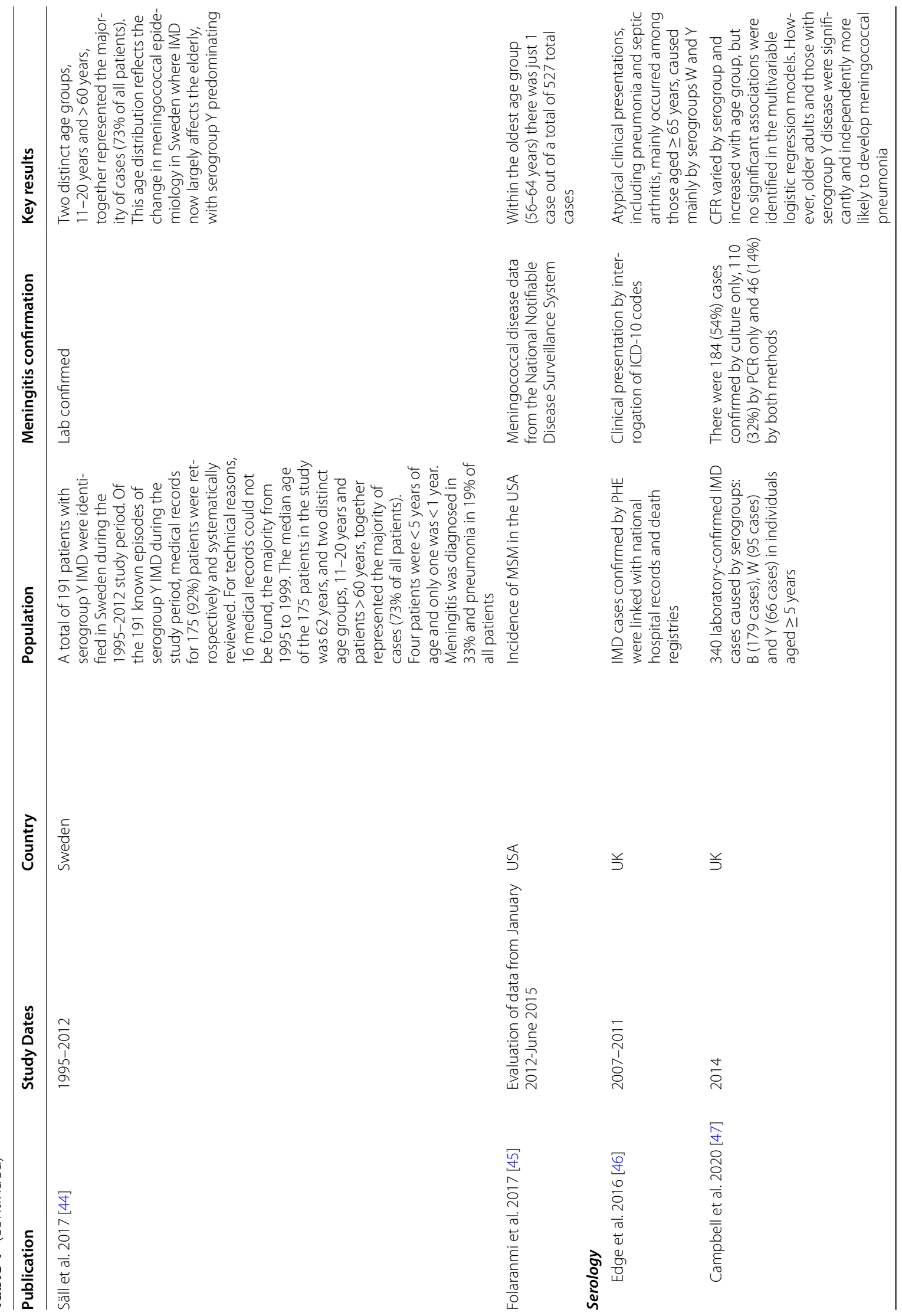




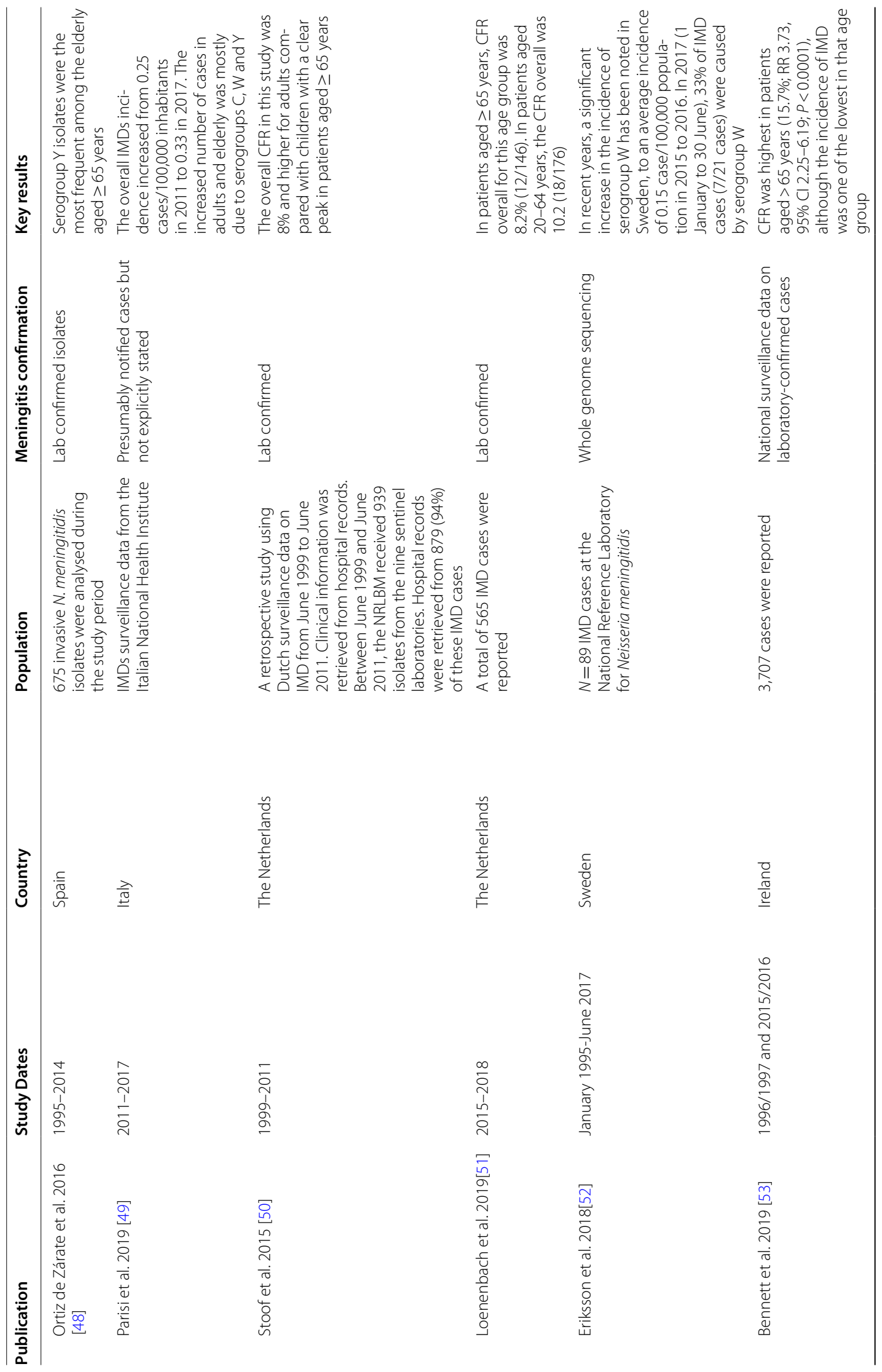


Guedes et al. BMC Public Health $\quad$ (2022) 22:380

Page 8 of 20

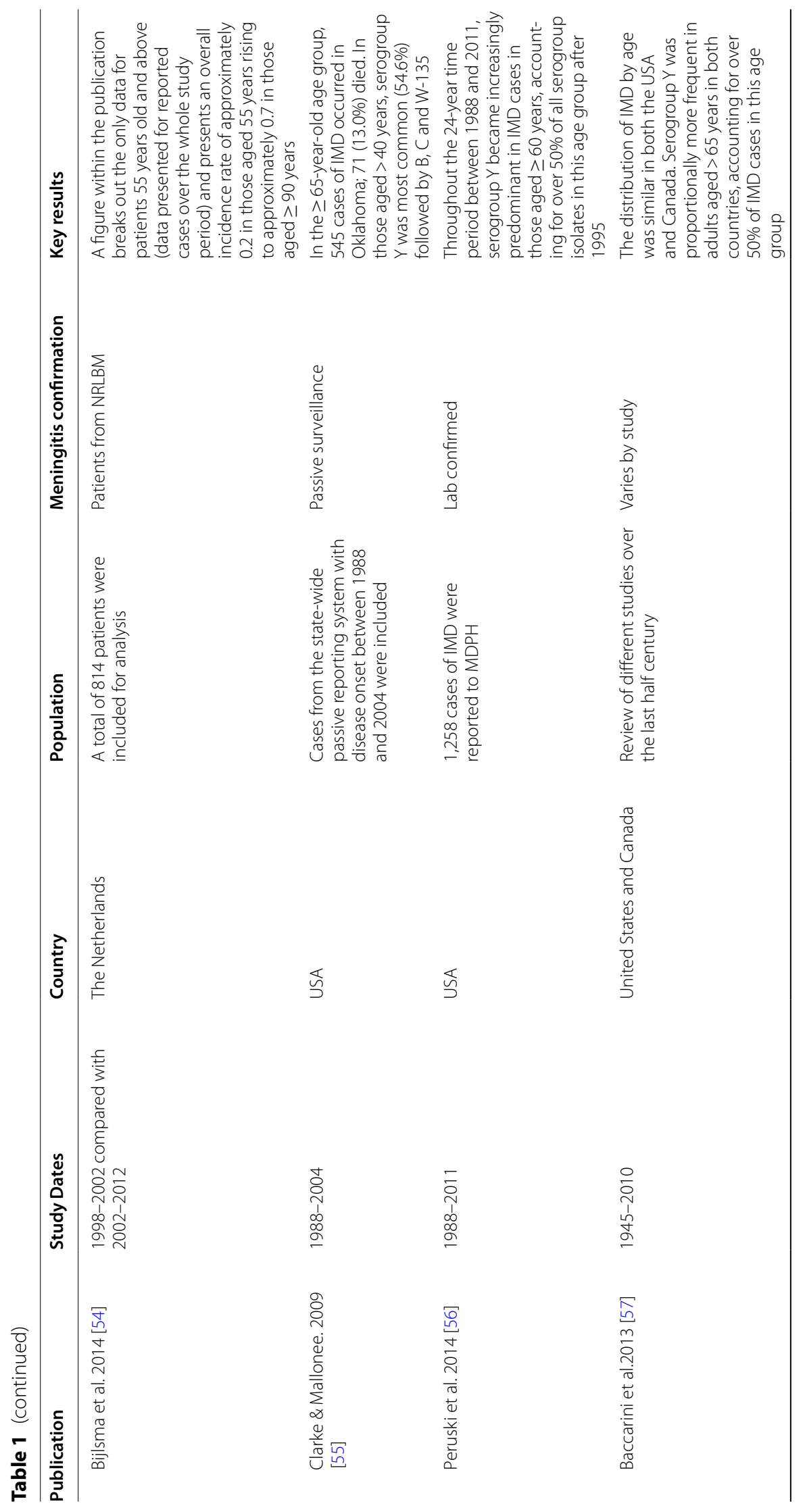




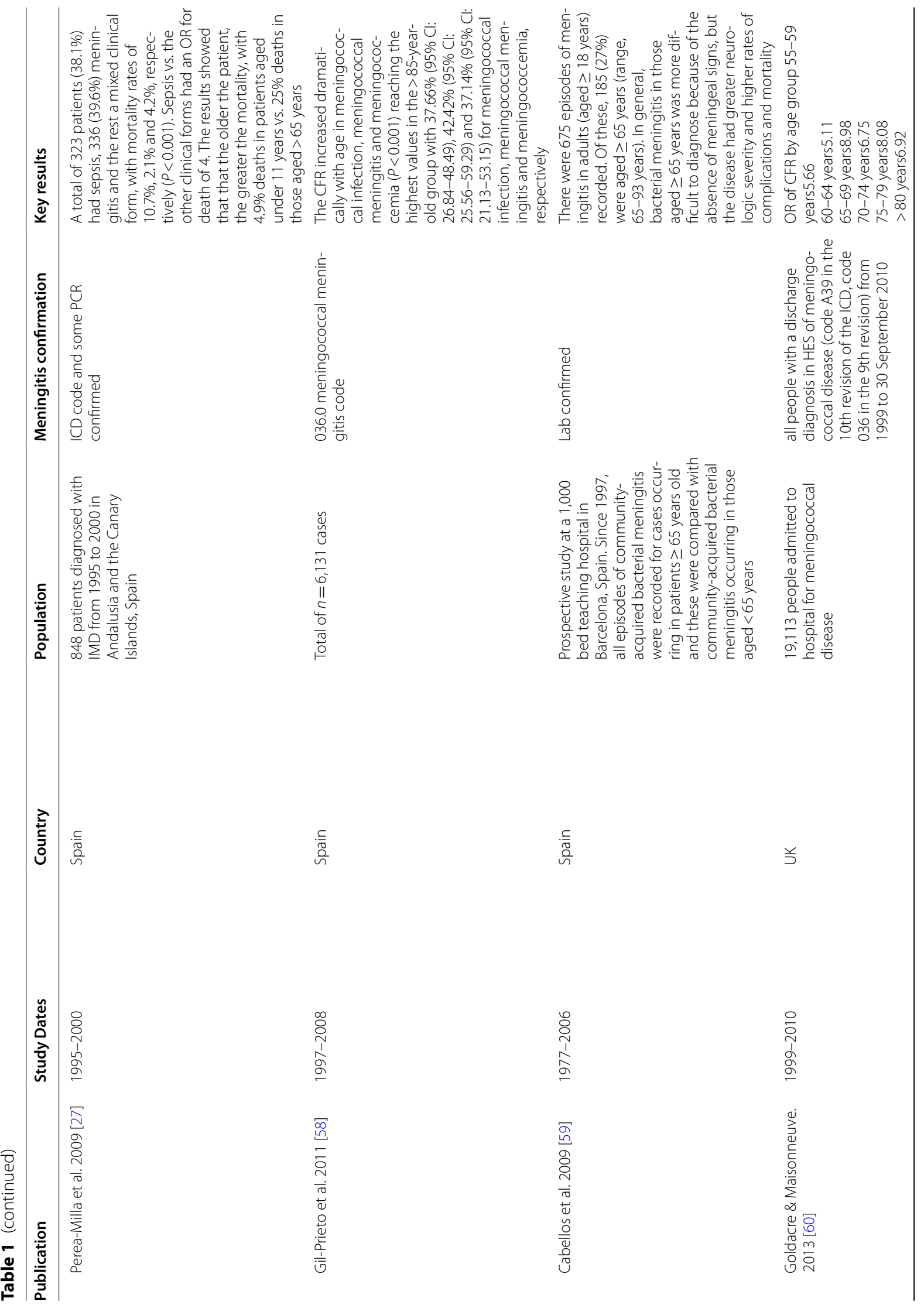




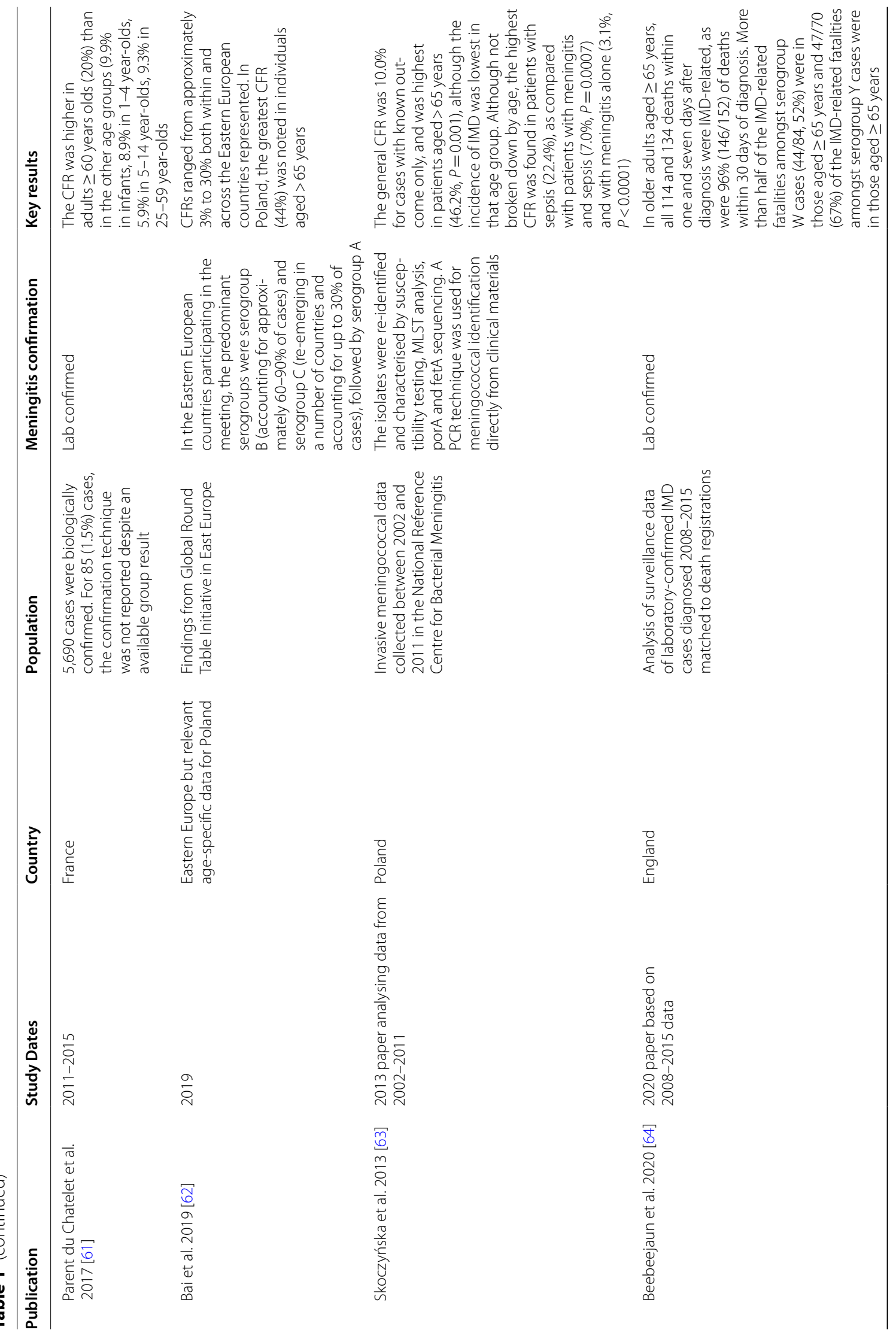




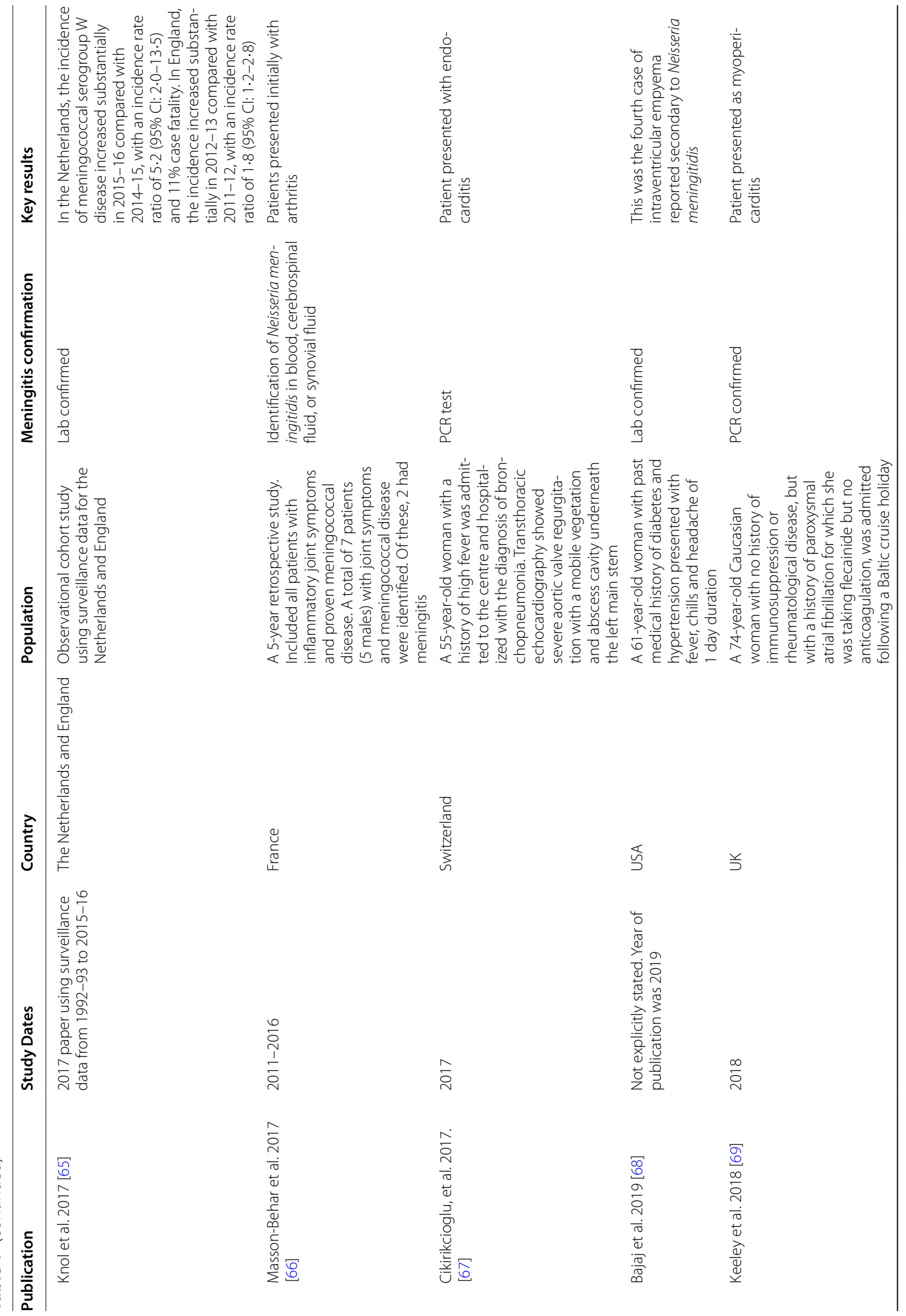




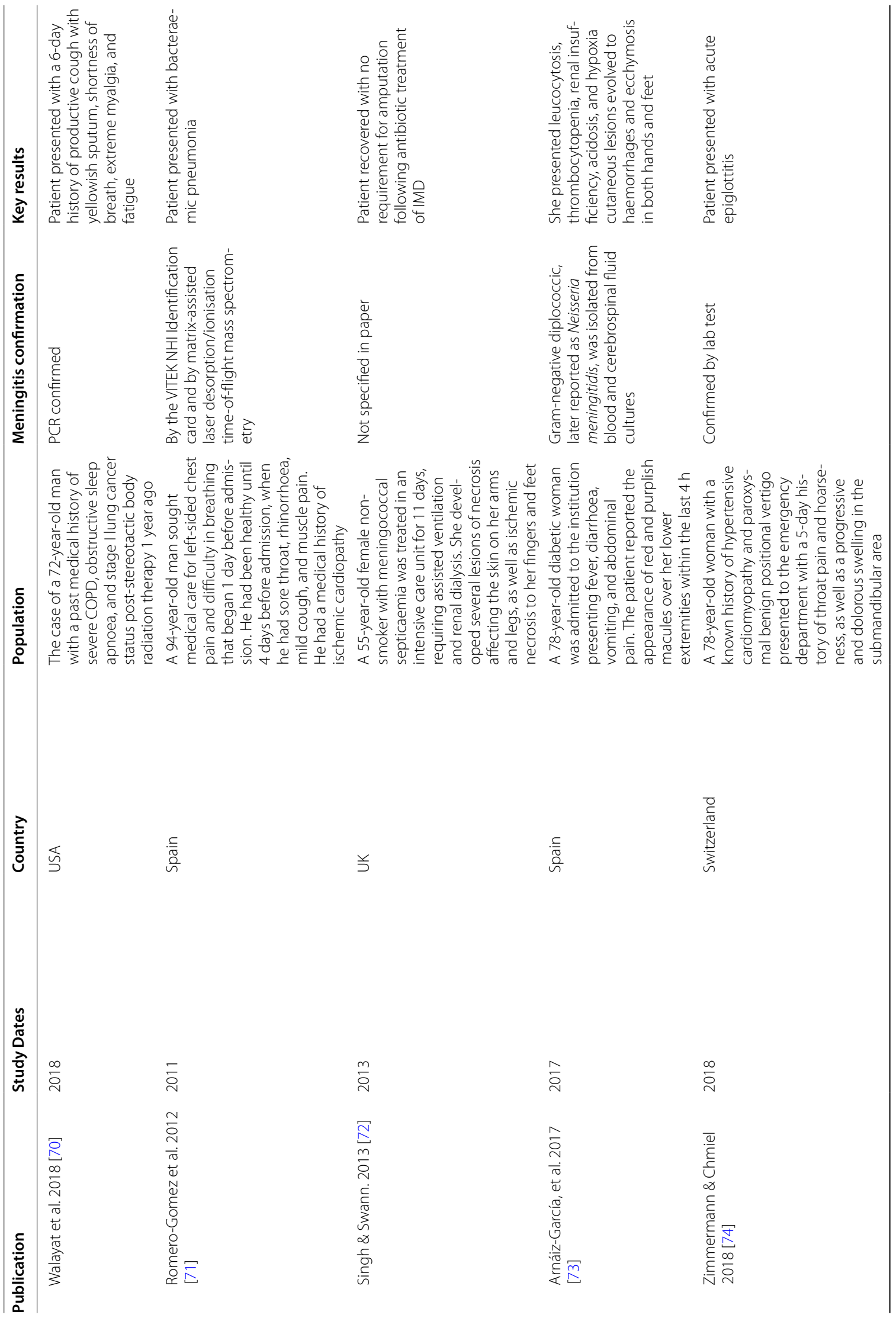




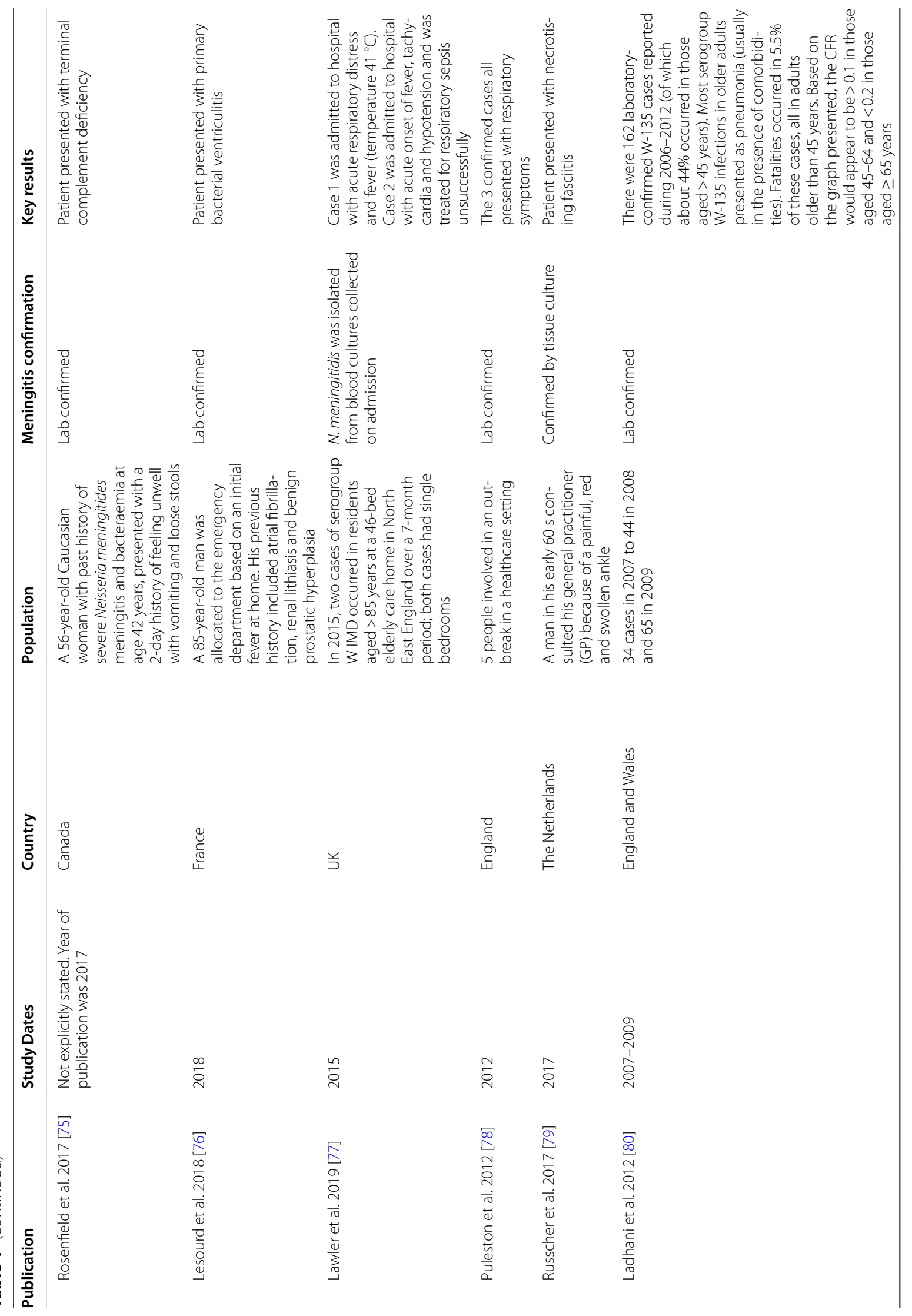


Guides et al. BMC Public Health <wide> (2022) 22:380

Page 14 of 20

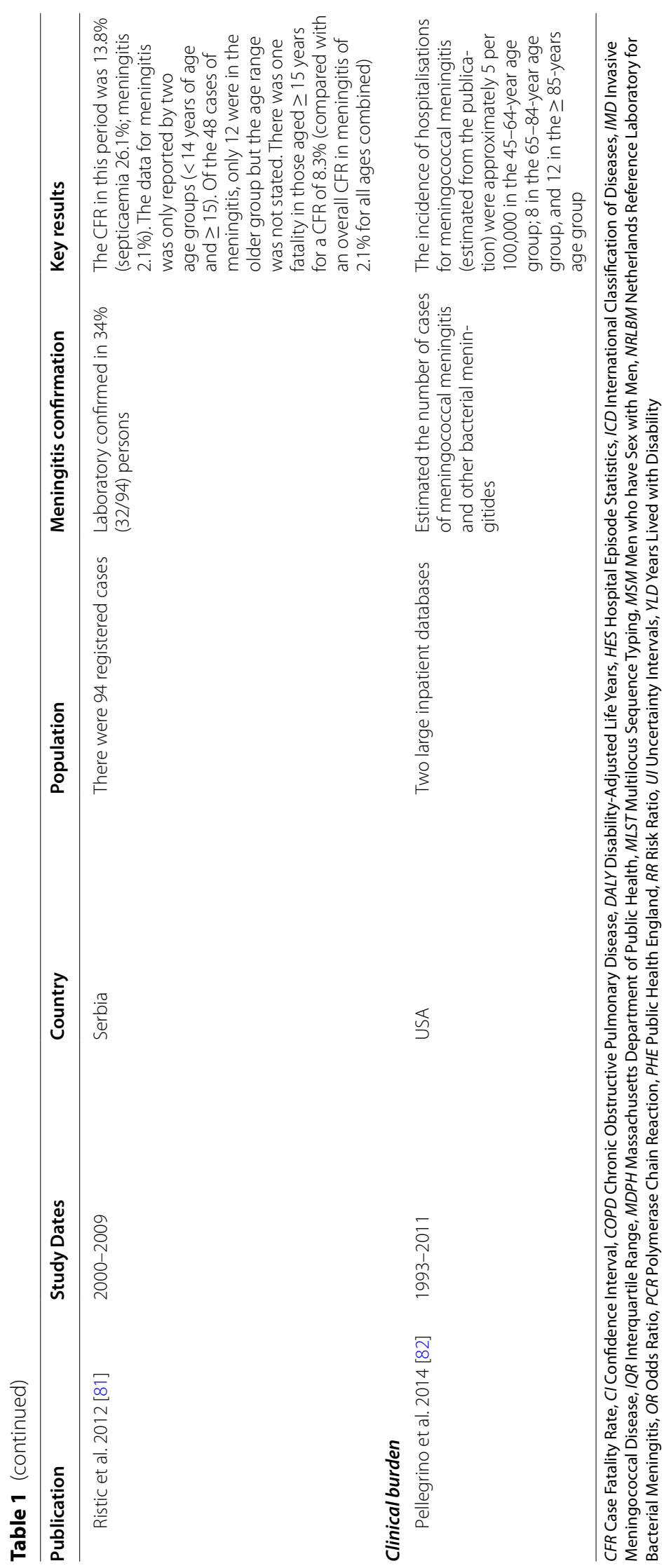


Therefore, underreporting of other serogroups may have caused an apparent increase in serogroup $\mathrm{Y}$ cases as a proportion of all cases.

\section{Mortality}

Many of the studies showed that case fatality rates (CFRs) were higher in older adults than in younger adults, adolescents and children. Global data over the period 2000 to 2017 from the Meningitis Research Foundation's Meningitis Progress Tracker [83] showed that the CFR for those aged $>65$ years averaged $12 \%$ compared with $7 \%$ for those aged 25-64 years.

Data from the ECDC [84] (during the period 19992018) showed that the CFR in those aged $\geq 50$ years remained relatively stable at $17.4-18.4 \%$ from 1999 to 2006 but decreased to approximately $14 \%$ in recent years. Multiple published studies in Europe also found higher CFRs in older adults, including those from Spain [27, $58,59]$, UK [46, 60, 78], Ireland [53], France [61] and the Netherlands [50]. These studies highlighted that existing comorbidities were an additional risk factor, and combining these with increased age may explain the poorer outcome in older adults. Eastern Europe appears to have much higher CFRs -ranging from approximately 3-46\% $[62,63]$. However, one single study undertaken in the Netherlands during 2015-2018 found higher CFRs in younger, rather than older, adults [51].

The 2018 surveillance report from the CDC [86] in the USA showed higher CFRs in patients aged $\geq 65$ years than that in those aged $25-64$ years $(23.3$ per 100 cases vs 14.1 per 100 cases). The CFRs were higher in these two age groups (25-64 and $\geq 65$ years) than in any other age group, including infants (overall average CFR was 12.0 per 100 cases). Other US studies support the higher CFRs observed in older adults $[55,56]$.

CFRs may also be higher in those affected by serogroups $\mathrm{W}$ and $\mathrm{Y}$, which as shown previously are more frequently the cause of IMD in older adults. The 2018 surveillance report from the CDC [86] reported higher CFR associated with serogroup W (23.5 per 100 cases with known outcome) than that for any other serogroup (overall CFR was 12.0\%). A similar finding was reported in a US study undertaken for the period 1945 to 2010 by Baccarini et al. [57]. Studies in the UK [64] and the Netherlands [65] have also noted higher CFRs associated with serogroup $\mathrm{W}$ and $\mathrm{Y}$ cases.

\section{Atypical clinical presentation}

We identified 20 case reports (12 females, 6 males and 2 cases where sex was not reported) from 17 papers [66-77, 79] concerning patients aged $\geq 55$ years (range 55-94 years) presenting with atypical symptoms (often linked to a comorbid condition) including myocarditis/ endocarditis and arthritis. Half of the total cases identified were patients living in Europe $(n=11), 2$ cases in North America, and 1 case where the location was not disclosed. In each case, IMD was not initially suspected and $N$. meningitidis was only detected once the patients were admitted to hospital. These case studies highlight the need to be aware of the potential for atypical clinical presentation, to ensure early recognition and treatment and to also allow for susceptibility testing and avoidance of inappropriate antibiotic use and treatment failure. Atypical IMD presentation may be more common in older adults, possibly resulting in delayed diagnosis [47, 78]. In addition, CFRs tended to be higher in those with underlying medical conditions or atypical clinical presentation $[27,57,63,80,81]$. There was no mention in any of the case reports of patients having being previously vaccinated.

\section{Clinical burden}

Only two studies that reported resource use in older adults with IMD were identified and both (one in the USA and one in Spain) found an increased incidence of hospitalisation among older adults compared with that in younger adults and adolescents $[58,82]$.

\section{Discussion}

This comprehensive literature review found evidence that IMD in older adults (those aged $\geq 55$ years of age) is mainly caused by serogroups $\mathrm{W}$ and $\mathrm{Y}$, which are generally not the predominant circulating strains in any given country or region, and older adults generally have higher CFRs than other age groups (likely linked to underlying comorbidities). Older adults also appear to be more likely to present with atypical symptoms. In addition, there appears to be a shift in IMD prevalence from younger to older people, attributed in part to the success of vaccination programmes against meningitis $C$ in infants and adolescents, but this may also be linked to other factors such as waning immunity amongst those previously vaccinated or immune senescence as a result of aging. Our results are consistent with previous studies which have shown similar trends over time in the epidemiology and clinical presentation of IMD; for example, the link between atypical clinical presentation and higher CFRs [23, 47, 59, 78, 89]. A recent meta analysis of the CFR for laboratory-confirmed IMD cases reported a CFR of $9.0 \%$ in infants, which gradually decreased to $7.0 \%$ in 7 -year olds, subsequently increased to $15.0 \%$ in young adults (aged $<28$ years), stabilised between 15 and $20 \%$ in mid-aged adults and reached a high in older adults [90]. Similar links between age and higher mortality have also previously been reported [4]. 
There is likely considerable underreporting of IMD cases worldwide. The MRF [83] noted that because meningitis deaths are based on national death registration rather than national surveillance estimates and that because $97 \%$ of cases occur in countries with either no or low quality data recording systems, the number of deaths would be substantially underestimated (although it should be noted this comment applies to meningitis in general and not that caused solely by Neisseria menigitidis). Improved surveillance systems could help improve disease monitoring. The Global Burden of Disease Study showed that six of the ten countries with the highest number of meningitis deaths (all-causes) are in the African meningitis belt region; though data for older adults from these countries are lacking, suggesting a potential underreporting of cases in older adults in this region [41, 91, 92]. Since we restricted our search to English langauge papers only we decided to exclude date from outside North American and Europe but it is interesting to note that we identified only eleven English language published studies of IMD in older adults from countries outside Europe or North America, which appers to be consistent with previous research highlighting the lack of regional data, particularly from South-East Asia and the Eastern Mediterranean [3] in non-native languages. It is also interesting to note that some of the data from these studies was consistent with the findings from Europe and North America with respect to serology and the shift in the incidence to older age groups [93, 94]. In addition, many of the publications identified in this review, despite having patients in the age group of interest, did not present data on clinical presentation and/or serogroups by age (and indeed when they did present these data, they tended to focus specifically on younger adults) or they presented all meningitis cases together without distinction by pathogenic cause [51, 95-100].

There is evidence to suggest that some risk groups are underrepresented in this review. It is worth noting that IMD cases in MSM are reported as a specific category within the CDC data, and multiple studies in this group have previously been published [101, 102]. There is evidence that younger men are more willing to be vaccinated than older men[103]. However, only a single study in this group was identified in the literature review and only one patient fell within the age range of interest, suggesting the predominant focus is possibly on younger men [45]. It also surprising that, with the exception of two case reports [77], there were no studies examining older adults living in nursing or residential care homes, where one might suspect that close contact between individuals could potentially lead to an increase in transmission of infectious diseases such as IMD.

Of note, the high CFRs observed in older adults in studies included in this review, up to $34 \%$ [104], are consistent with those reported in a recent meta-analysis of laboratory-confirmed IMD. In addition, the meta-analysis also showed that CFRs generally increased with age and were highest in the oldest age groups [90]. As such, older adults represent an unmet need for meningococcal vaccination because, as noted by Trezikowski de Lima et al. [105] "given the increasing proportion of older people in the population and the high CFR of meningococcal disease in the elderly, it would be interesting to evaluate the insertion of these vaccines in the immunization programs for this age group...also, vaccines can generate other benefits, e.g. lower overall cost of healthcare".

The strengths of this study were that it included a comprehensive literature review and grey literature search to supplement the data derived from publications. However, there was relatively little information on IMD in older adults, and the difficulties of interpreting the results were compounded by the inconsistent reporting by age group, or where demographic breakdown of a study population was presented in detail the subsequent results (e.g. epidemiology, clinical presentations) were only presented for the cohort as a whole. The issue is further complicated by the lack of standardised case definitions, changes to national immunisation programmes over time and the varying surveillance and laboratory techniques employed worldwide, as commonly acknowledged [106, 107]. As such, there remains the need for more specific age-related studies and improvements in consistency of reporting across all age groups, including older adults $[108,109]$.

It should also be noted that the data presented here predate the severe acute respiratory syndrome coronavirus 2 pandemic and the introduction of coronavirus disease 2019 (COVID-19) control measures; social distancing and shielding appear to have led to a decrease in recorded cases of IMD in some countries [110]. However, IMD cases that were associated with respiratory presentations of which some corresponded to suspected COVID-19 appeared to increase in 2020 compared with $2018(P=0.029)$ and $2019(P=0.002)$ and involved the elderly and with unusual isolates [111]. Moreover, IMD concomitant with COVID-19 may be associated with poorer outcomes in the elderly, because the prognosis of either disease is usually worse in this age group, though definitive data are lacking. Nonetheless, IMD burden would likely return to previous levels once on-going COVID-19 measures are relaxed, and as such continued surveillance for meningococcal and invasive bacterial infections will also be important 
as the pandemic progresses. The authors of the latter study [111] concluded that surveillance of IMD should be improved and vaccination against meningococcal disease in older adults should be considered (currently only Italy suggests adopting a lifelong approach to vaccination, with regular immunisation being offered to adults in the future) [112].

\section{Conclusions}

This comprehensive literature review, supplemented by data from national organisations, institutions and societies provides evidence that older adults (those aged $\geq 55$ years) with IMD are mainly affected by serogroups $\mathrm{W}$ and $\mathrm{Y}$, which are generally not the predominant strains in circulation in any country. Older adults have the highest CFRs, probably linked to underlying comorbidities and more atypical presentations hindering appropriate timely diagnosis and management. In addition, there has been a shift in the incidence of IMD from younger to older adults, which may be attributed to the success of meningococcal vaccination programmes, although the exact scale of this shift is difficult to quantify. Future research should evaluate the alternative options of either implementating adolescent vaccination programmes with conjugate vaccines in some countries that may lead to indirect protection in older adults or te use of meningococcal vaccines that include coverage against serogroups $\mathrm{W}$ and $\mathrm{Y}$ in immunization programs for older adults to help inform health authorities' decisions of the benefits of vaccination and the utility of expanding national immunization programmes to extend protection to older adults.

\begin{abstract}
Abbreviations
ABCs: Active Bacterial Core surveillance; ASM: American Society for Microbiology; CDC: Centers for Disease Control and Prevention; CFR: Case Fatality Rate; $95 \%$ Cl: 95\% Confidence Interval; CoMO: Confederation of Meningitis Organisations; COVID-19: Coronavirus disease 2019; ECDC: European Centre for Disease Prevention and Control; EEA: European Economic Area; ESCMID: European Society of Clinical Microbiology and Infectious Diseases; ESPID: European Society for Paediatric Infectious Diseases; EU: European Union; HPS: Health Protection Scotland; IDSA: Infectious Diseases Society of America; IHME: Institute for Health Metrics and Evaluation; IMD: Invasive Meningococcal Disease; ISID: International Society for Infectious Diseases; MRF: Meningitis Research Foundation; MSM: Men who have Sex with Men; NICE: National Institute for Health and Care Excellence; PHE: Public Health England; UK: United Kingdom; USA: United States of America; WHO: World Health Organization; YLD: Years of Life lived with Disability.
\end{abstract}

\section{Supplementary Information}

The online version contains supplementary material available at https://doi. org/10.1186/s12889-022-12795-9.

\section{Additional file 1.}

\section{Acknowledgements}

The authors acknowledge Richard Glover and Tim Mills of inScience Communications, Springer Healthcare Ltd, Chester, UK for editorial assistance with the preparation of this manuscript. This assistance was funded by Sanofi Pasteur. The authors also thank Jean-Sebastien Persico for editorial assistance and manuscript coordination on behalf of Sanofi Pasteur.

\section{Authors' contributions}

SG - Conceptualization, methodology, investigation, Writing - review and editing. IBG - Methodology, investigation, Writing - review and editing. KE methodology, investigation, Writing - review and editing. FC -investigation, Writing - review and editing. PO - Conceptualization, methodology, investigation, Writing - review and editing. The author(s) read and approved the final manuscript.

\section{Funding}

This review was funded by Sanofi Pasteur.

\section{Availability of data and materials}

All data generated or analysed during this study from published articles or conference presentations are included in this published article (Table 1). Any data generated or analysed from international or national organisations is available from the weblinks presented in Supplementary Table 2.

\section{Declarations}

Ethics approval and consent to participate

Not applicable

\section{Consent for publication}

Not applicable

\section{Competing interests}

PO, FC and IBG are employees of Sanofi Pasteur and may hold shares in the company. SG was an employee of Sanofi Pasteur at the time of this review. KE is an employee of InScience Communications, Springer Healthcare Ltd, Chester, UK, which was contracted by Sanofi Pasteur to undertake the literature searches and provide editorial assistance.

\section{Author details}

${ }^{1}$ Sanofi Pasteur, 14 Espace Henry Vallée, 69007 Lyon, France. ${ }^{2}$ InScience Communications, Chester, UK.

Received: 30 September 2021 Accepted: 10 February 2022

Published online: 23 February 2022

\section{References}

1. Dwilow R, Fanella S. Invasive meningococcal disease in the 21st century - an update for the clinician. Curr Neurol Neurosci Rep. 2015;15(3):2.

2. Hedari CP, Khinkarly RW, Dbaibo GS. Meningococcal serogroups A, C, W-135, and $Y$ tetanus toxoid conjugate vaccine: a new conjugate vaccine against invasive meningococcal disease. Infect Drug Resist. 2014;7:85-99.

3. Jafri RZ, Ali A, Messonnier NE, Tevi-Benissan C, Durrheim D, Eskola J, Fermon F, Klugman KP, Ramsay M, Sow S, et al. Global epidemiology of invasive meningococcal disease. Popul Health Metr. 2013;11(1):17.

4. Strelow VL, Vidal JE. Invasive meningococcal disease. Arq Neuropsiquiatr. 2013;71(9B):653-8.

5. Raja NS, Parasakthi N, Puthucheary SD, Kamarulzaman A. Invasive meningococcal disease in the University of Malaya Medical Centre, Kuala Lumpur. Malaysia J Postgrad Med. 2006;52(1):23-9 discussion 29.

6. Fransen F, Heckenberg SGB, Hamstra HJ, Feller M, Boog CJP, van Putten JPM, van de Beek D, van der Ende A, van der Ley P. Naturally occurring lipid a mutants in Neisseria meningitidis from patients with invasive meningococcal disease are associated with reduced coagulopathy. PLoS Pathog. 2009;5(4):e1000396. 
7. Kinlin LM, Spain CV, Ng V, Johnson CC, White ANJ, Fisman DN. Environmental exposures and invasive meningococcal disease: an evaluation of effects on varying time scales. Am J Epidemiol. 2009;169(5):588-95.

8. Sadarangani M, Scheifele DW, Halperin SA, Vaudry W, Le Saux N, Tsang $\mathrm{R}$, Bettinger JA, investigators of the Canadian Immunization Monitoring Program A. Outcomes of invasive meningococcal disease in adults and children in Canada between 2002 and 2011: a prospective cohort study. Clin Infect Dis. 2015;60(8):e27-35.

9. Anonychuk A, Woo G, Vyse A, Demarteau N, Tricco AC. The cost and public health burden of invasive meningococcal disease outbreaks: a systematic review. Pharmacoeconomics. 2013;31 (7):563-76.

10. WangHaji Ali AfzaliMarshall BHH. The inpatient costs and hospital service use associated with invasive meningococcal disease in South Australian children. Vaccine. 2014;32(37):4791-8.

11. Wang B, Santoreneos R, Afzali H, Giles L, Marshall H. Costs of invasive meningococcal disease: a global systematic review. Pharmacoeconomics. 2018;36(10):1201-22.

12. Rampakakis E, Vaillancourt J, Mursleen S, Sampalis JS. Healthcare resource utilization and cost of invasive meningococcal disease in Ontario Canada. Pediatr Infect Dis J. 2019;38(3):253-7.

13. Scholz S, Koerber F, Meszaros K, Fassbender RM, Ultsch B, Welte RR, Greiner W. The cost-of-illness for invasive meningococcal disease caused by serogroup B Neisseria meningitidis (MenB) in Germany. Vaccine. 2019;37(12):1692-701.

14. Wang B, Haji Ali Afzali H, Giles L, Marshall H. Lifetime costs of invasive meningococcal disease: a markov model approach. Vaccine. 2019;37(46):6885-93.

15. Huang L, Heuer OD, Janßen S, Häckl D, Schmedt N. Clinical and economic burden of invasive meningococcal disease: evidence from a large German claims database. PLoS One. 2020;15(1):e0228020.

16. Strifler L, Morris SK, Dang V, Tu HAT, Minhas RS, Jamieson FB, Deeks SL, Crowcroft NS, Sander B. The health burden of invasive meningococcal disease: a systematic review. J Pediatric Infect Dis Soc. 2016;5(4):417-30.

17. Olbrich KJ, Müller D, Schumacher S, Beck E, Meszaros K, Koerber F. Systematic review of invasive meningococcal disease: sequelae and quality of life impact on patients and their caregivers. Infect Dis Ther. 2018;7(4):421-38.

18. Bröker M, Cooper B, Detora LM, Stoddard JJ. Critical appraisal of a quadrivalent CRM(197) conjugate vaccine against meningococcal serogroups A, CW-135 and Y (Menveo) in the context of treatment and prevention of invasive disease. Infect Drug Resist. 2011;4:137-47.

19. Bronska E, Kalmusova J, Dzupova O, Maresova V, Kriz P, Benes J. Dynamics of PCR-based diagnosis in patients with invasive meningococcal disease. Clin Microbiol Infect. 2006;12(2):137-41.

20. Garlicki A, Bociqga-Jasik M, Kalinowska-Nowak A. Invasive meningococcal disease-management and treatment. Przegl Epidemiol. 2008;62(Suppl 1):39-44.

21. Nagel FW, Ezeoke I, Antwi M, Del Rosso PE, Dorsinville M, Isaac BM Hayden A, Hoffman RS, Weingart SD, Weiss D. Delayed recognition of fatal invasive meningococcal disease in adults. JMM Case Rep. 2016;3(3):e005027.

22. Waterfield T, Fairley D, Lynn F, Blackwood B, Shields MD. A protocol for a systematic review of the diagnostic accuracy of loop-mediated-isothermal amplification (LAMP) in diagnosis of invasive meningococcal disease in children. Syst Rev. 2018;7(1):86.

23. Stinson C, Burman C, Presa J, Abalos M. Atypical presentation of invasive meningococcal disease caused by serogroup W meningococci. Epidemiol Infect. 2020;148:e12.

24. Guiddir T, Gros M, Hong E, Terrade A, Denizon M, Deghmane AE, Taha MK. Unusual initial abdominal presentations of invasive meningococcal disease. Clin Infect Dis. 2018;67(8):1220-7.

25. Vienne P, Ducos-Galand M, Guiyoule A, Pires R, Giorgini D, Taha MK, Alonso JM. The role of particular strains of Neisseria meningitidis in meningococcal arthritis, pericarditis, and pneumonia. Clin Infect Dis. 2003;37(12):1639-42.

26. Pelton SI, Gilmet GP. Expanding prevention of invasive meningococcal disease. Expert Rev Vaccines. 2009;8(6):717-27.

27. Perea-Milla E, Olalla J, Sánchez-Cantalejo E, Martos F, Matute-Cruz P, Carmona-López G, Fornieles Y, Cayuela A, García-Alegría J. ANCA Group: pre-hospital antibiotic treatment and mortality caused by invasive meningococcal disease, adjusting for indication bias. BMC Public Health. 2009;9:95.

28. Papaevangelou V, Spyridis N. MenACWY-TT vaccine for active immunization against invasive meningococcal disease. Expert Rev Vaccines. 2012;11(5):523-37.

29. Nadel S, Ninis N. Invasive meningococcal disease in the vaccine era. Front Pediatr. 2018;6:321.

30. Halperin SA, Bettinger JA, Greenwood B, Harrison LH, Jelfs J, Ladhani SN, McIntyre P, Ramsay ME, Safadi MA. The changing and dynamic epidemiology of meningococcal disease. Vaccine. 2012;30(Suppl 2):B26-36.

31. Purmohamad A, Abasi E, Azimi T, Hosseini S, Safari H, Nasiri MJ, ImaniFooladi AA. Global estimate of Neisseria meningitidis serogroups proportion in invasive meningococcal disease: a systematic review and meta-analysis. Microb Pathog. 2019;134:103571.

32. Neri A, Pezzotti P, Fazio C, Vacca P, D'Ancona FP, Caporali MG, Stefanelli P. Epidemiological and molecular characterization of invasive meningococcal disease in Italy, 2008/09-2012/13. PLoS One. 2015;10(10):e0139376.

33. Siu T, Tang W, Dawar M, Patrick DM. Impact of routine immunization using meningococcal $\mathrm{C}$ conjugate vaccine on invasive meningococcal disease in British Columbia. Can J Public Health. 2008;99(5):380-2.

34. Hellenbrand W, Elias J, Wichmann O, Dehnert M, Frosch M, Vogel U. Epidemiology of invasive meningococcal disease in Germany, 2002-2010, and impact of vaccination with meningococcal C conjugate vaccine. J Infect. 2013;66(1):48-56.

35. Gunaratnam P, Massey P, Durrheim D, Torvaldsen S. Invasive meningococcal disease in elderly people, New South Wales, Australia, 1993 to 2012. Western Pac Surveill Response J. 2013;4(4):4-10.

36. Whittaker R, Dias JG, Ramliden M, Ködmön C, Economopoulou A, Beer N, Pastore Celentano L. ECDC network members for invasive meningococcal disease: the epidemiology of invasive meningococcal disease in EU/EEA countries, 2004-2014. Vaccine. 2017;35(16):2034-41.

37. Igidbashian S, Bertizzolo L, Tognetto A, Azzari C, Bonanni P, Castiglia P, Conversano M, Esposito S, Gabutti G, Icardi G, et al. Invasive meningococcal disease in Italy: from analysis of national data to an evidencebased vaccination strategy. J Prev Med Hyg. 2020;61(2):E152-61.

38. Berghold C, Berghold A, Fülöp G, Heuberger S, Strauss R, Zenz W. Invasive meningococcal disease in Austria 2002: assessment of completeness of notification by comparison of two independent data sources. Wien Klin Wochenschr. 2006;1 18(1-2):31-5.

39. Vázquez JA, Taha MK, Findlow J, Gupta S, Borrow R. Global meningococcal Initiative: guidelines for diagnosis and confirmation of invasive meningococcal disease. Epidemiol Infect. 2016;144(14):3052-7.

40. Marten O, Koerber F, Bloom D, Bullinger M, Buysse C, Christensen H, De Wals P, Dohna-Schwake C, Henneke P, Kirchner M, et al. A DELPHI study on aspects of study design to overcome knowledge gaps on the burden of disease caused by serogroup B invasive meningococcal disease. Health Qual Life Outcomes. 2019;17(1):87.

41. GBD 2016 Meningitis Collaborators. Global, regional, and national burden of meningitis, 1990-2016: a systematic analysis for the Global Burden of Disease Study 2016. Lancet Neurol. 2018;17(12):1061-82.

42. Gray S, Campbell H, Walker A, Patel S, Willerton L, Lekshmi A, Clark S, Bai $X$, Ribeiro S, Parikh $S$ et al. Epidemiology and surveillance of meningococcal disease in England. 2019. https://www.meningitis.org/getmedia/ 6c45bf47-f09a-4771-87b2-8ed57fc0b67d/Dr-Steve-Gray?disposition= attachment. Accessed 11 Nov 2020. In., vol. 2020; 2019.

43. Stefanelli P, Fazio C, Neri A, Di Taranto A, Labonia M, De Robertis AL, Loconsole D, Martinelli D, Chironna M. Twenty years of surveillance of invasive meningococcal diseases in Puglia Italy. Ann Ist Super Sanita. 2015;51(4):366-70.

44. Säll O, Stenmark B, Glimåker M, Jacobsson S, Mölling P, Olcén P, Fredlund $\mathrm{H}$. Clinical presentation of invasive disease caused by Neisseria meningitidis serogroup Y in Sweden, 1995 to 2012. Epidemiol Infect. 2017;145(10):2137-43.

45. Folaranmi TA, Kretz CB, Kamiya H, MacNeil JR, Whaley MJ, Blain A, Antwi M, Dorsinville M, Pacilli M, Smith S, et al. Increased risk for meningococcal disease among men who have sex with men in the United States, 2012-2015. Clin Infect Dis. 2017;65(5):756-63.

46. Edge C, Waight P, Ribeiro S, Borrow R, Ramsay M, Ladhani S. Clinical diagnoses and outcomes of 4619 hospitalised cases of 
laboratory-confirmed invasive meningococcal disease in England: linkage analysis of multiple national databases. J Infect. 2016;73(5):427-36.

47. Campbell H, Andrews N, Parikh S, Ribeiro S, Gray S, Lucidarme J, Ramsay ME, Borrow R, Ladhani SN. Variable clinical presentation by the main capsular groups causing invasive meningococcal disease in England. J Infect. 2020;80(2):182-9.

48. Ortiz de Zárate J, Arana M, Asencor M, Mojica C, Trallero E. Epidemiology and characterization of invasive Neisseria meningitidis serogroup Y isolates in Basque country (Northern Spain) from 1995 to 2014. 2016. https://www.escmid.org/escmid_publications/escmid_elibrary/mater $\mathrm{ial} /$ ?mid=45891. Accessed $24 \mathrm{Mar}$ 2021. In., vol. 2021; 2016.

49. Parisi S, Azzari C, Bonanni P, Castiglia P, Conversano M, Icardi G, Tognetto A, Checcucci Lisi G. Invasive meningococcal diseases in Italy: an analysis of national surveillance data, 2011-2017. 2019. https://espidmeeting. org/wp-content/uploads/sites/21/2019/05/ESPID-2019-AcceptedAbstracts-Listed.pdf. Accesssed 24 Mar 2021. In., vol. 2021; 2019.

50. Stoof SP, Rodenburg GD, Knol MJ, Rümke LW, Bovenkerk S, Berbers GAM, Spanjaard L, van der Ende A, Sanders EAM. Disease burden of invasive meningococcal disease in the Netherlands between June 1999 and June 2011: a subjective role for serogroup and clonal complex. Clin Infect Dis. 2015;61 (8):1281-92.

51. Loenenbach AD, van der Ende A, de Melker HE, Sanders EAM, Knol MJ. The clinical picture and severity of invasive meningococcal disease serogroup W compared with other serogroups in the Netherlands, 2015-2018. Clin Infect Dis. 2020;70(10):2036-44.

52. Eriksson L, Hedberg ST, Jacobsson S, Fredlund H, Mölling P, Stenmark B. Whole-genome sequencing of emerging invasive Neisseria meningitidis serogroup W in Sweden. J Clin Microbiol. 2018;56(4):e01409-01417.

53. Bennett D, O'Lorcain P, Morgan S, Cotter S, Cafferkey M, Cunney R. Epidemiology of two decades of invasive meningococcal disease in the Republic of Ireland: an analysis of national surveillance data on laboratory-confirmed cases from 1996 to 2016. Epidemiol Infect. 2019;147:e142.

54. Bijlsma MW, Brouwer MC, Kasanmoentalib ES, Kloek AT, Lucas MJ, Tanck MW, van der Ende A, van de Beek D. Community-acquired bacterial meningitis in adults in the Netherlands, 2006-14: a prospective cohort study. Lancet Infect Dis. 2016;16(3):339-47.

55. Clarke C, Mallonee S. State-based surveillance to determine trends in meningococcal disease. Public Health Rep. 2009;124(2):280-7.

56. Peruski AH, Kludt P, Patel RS, DeMaria A. Secular trends in invasive meningococcal disease, Massachusetts, 1988-2011: what happened to invasive disease? Epidemiol Infect. 2014;142(12):2483-90.

57. Baccarini C, Ternouth A, Wieffer $H$, Vyse A. The changing epidemiology of meningococcal disease in North America 1945-2010. Hum Vaccin Immunother. 2013;9(1):162-71.

58. Gil-Prieto R, García-García L, Alvaro-Meca A, González-Escalada A, Viguera Ester P, De GilMiguel A. The burden of hospitalizations for meningococcal infection in Spain (1997-2008). Vaccine. 2011;29(34):5765-70.

59. Cabellos C, Verdaguer R, Olmo M, Fernández-Sabé N, Cisnal M, Ariza J, Gudiol F, Viladrich PF. Community-acquired bacterial meningitis in elderly patients: experience over 30 years. Medicine (Baltimore). 2009;88(2):115-9.

60. Goldacre MJ, Maisonneuve JJ. Mortality from meningococcal disease by day of the week: english national linked database study. J Public Health (Oxf). 2013;35(3):413-21.

61. du ParentChatelet I, Deghmane AE, Antona D, Hong E, Fonteneau L, Taha MK, Levy-Bruhl D. Characteristics and changes in invasive meningococcal disease epidemiology in France, 2006-2015. J Infect. 2017;74(6):564-74.

62. Bai X, Borrow R, Bukovski S, Caugant DA, Culic D, Delic S, Dinleyici EC, Eloshvili M, Erdősi T, Galajeva J, et al. Prevention and control of meningococcal disease: updates from the global meningococcal initiative in Eastern Europe. J Infect. 2019;79(6):528-41.

63. Skoczyńska A, Waśko I, Kuch A, Kadłubowski M, Gołębiewska A, Foryś M, Markowska M, Ronkiewicz P, Wasiak K, Kozińska A, et al. A decade of invasive meningococcal disease surveillance in Poland. PloS One. 2013;8(8):e71943.
64. Beebeejaun K, Parikh SR, Campbell H, Gray S, Borrow R, Ramsay ME, Ladhani SN. Invasive meningococcal disease: timing and cause of death in England, 2008-2015. J Infect. 2020;80(3):286-90.

65. Knol MJ, Hahné SJM, Lucidarme J, Campbell H, de Melker HE, Gray SJ, Borrow R, Ladhani SN, Ramsay ME, van der Ende A. Temporal associations between national outbreaks of meningococcal serogroup $W$ and $C$ disease in the Netherlands and England: an observational cohort study. Lancet Public Health. 2017;2(10):e473-82.

66. Masson-Behar V, Jacquier H, Richette P, Ziza J-M, Zeller V, Rioux C, Coustet B, Dieudé P, Ottaviani S. Arthritis secondary to meningococcal disease: a case series of 7 patients. Medicine (Baltimore). 2017;96(29):e7573.

67. Cikirikcioglu M, Schrenzel J, Emonet S, Muller H, Ellenberger C, Giraud R, Kaiser L, Huber C. Keep in mind extremely rare etiologies!! Meningococcal aortic valve endocarditis. Kardiovaskulare Medizin. 2017;20(5):S123.

68. Bajaj D, Agrawal A, Gandhi D, Varughese R, Gupta S, Regelmann D. Intraventricular empyema caused by Neisseria meningitidis. IDCases. 2019;15:e00503.

69. Keeley AJ, Hammersley D, Dhamrait SS. A case of myopericarditis caused by Neisseria meningitidis W135 serogroup with protracted inflammatory syndrome. Clin Med (Lond). 2018;18(3):253-5.

70. Walayat S, Hussain N, Malik AH, Vazquez-Melendez E, Aulakh BS, Lynch T. Invasive meningococcal disease without meningitis: a forgotten diagnosis. Int Med Case Rep J. 2018;11:87-90.

71. Romero-Gomez MP, Rentero Z, Paño JR, Mingorance J. Bacteraemic pneumonia caused by Neisseria meningitidis serogroup Y. Respir Med Case Rep. 2012;5(1):23-4.

72. Singh D, Swann A. Skin demarcation and amputation level for foot gangrene following meningococcal septicemia. Foot Ankle Spec. 2013;6(5):384-8.

73. Arnáiz-García ME, Arnáiz-García AM, Gutierrez-Diez F, Nistal JF, González-Santos JM, Pulitani I, Amado-Diago C, Arnáiz J. Mutilating purpura fulminans in an adult with meningococcal sepsis. P R Health Sci J. 2017:36(3):179-82.

74. Zimmermann T, Chmiel C. Neisseria meningitidis sepsis in a patient with acute epiglottitis and respiratory failure. BMJ Case Rep. 2018;2018:bcr2017223388.

75. Rosenfield L, Cvetkovic A, Woodward K, Quirt J. Late presentation of possible terminal compliment deficiency with recurrent Neisseria meningitides infection. Allergy Asthma Clin Immunol. 2017;13(Suppl 1):A38.

76. Lesourd A, Magne N, Soares A, Lemaitre C, Taha M-K, Gueit I, Wolff M, Caron F. Primary bacterial ventriculitis in adults, an emergent diagnosis challenge: report of a meningoccal case and review of the literature. BMC Infect Dis. 2018;18(1):226.

77. Lawler J, Lucidarme J, Parikh S, Smith L, Campbell H, Borrow R, Gray S, Foster K, Ladhani S. Suspected cluster of Neisseria meningitidis W invasive disease in an elderly care home: do new laboratory methods aid public health action? United Kingdom, 2015. Euro Surveill. 2019;24(23):1900070.

78. Puleston R, Beck C, Tahir M, Bardhan M, Charlemagne P, Alves C, Ladhani S, Watson C, Ramsay M, Kaczmarksi E, et al. An unusual transmission event of Neisseria meningitidis serogroup W135 type 2a in a healthcare setting, England, 2012. Euro Surveill. 2012;17(44):20308.

79. Russcher A, Fanoy E, van Olden GDJ, Graafland AD, van der Ende A, $\mathrm{Knol} \mathrm{MJ}$. Necrotising fasciitis as atypical presentation of infection with emerging Neisseria meningitidis serogroup W (MenW) clonal complex 11, the Netherlands, March 2017. Euro Surveill. 2017;22(23):30549.

80. Ladhani SN, Lucidarme J, Newbold LS, Gray SJ, Carr AD, Findlow J, Ramsay ME, Kaczmarski EB, Borrow R. Invasive meningococcal capsular group Y disease, England and Wales, 2007-2009. Emerg Infect Dis. 2012;18(1):63-70

81. Ristic M, Seguljev Z, Petrovic V, Rajcevic S. Epidemiological charactheristics of meningococcal disease in Vojvodina (Serbia) at the beggining of 21st Century. HealthMED. 2012;6(7):2550-4.

82. Pellegrino P, Carnovale C, Perrone V, Salvati D, Gentili M, Brusadelli T, Antoniazzi S, Pozzi M, Radice S, Clementi E. Epidemiological analysis on two decades of hospitalisations for meningitis in the United States. Eur J Clin Microbiol Infect Dis. 2014;33(9):1519-24.

83. Meningitis progress tracker [https://www.meningitis.org/mpt] 
84. Disease data from ECDC surveillance atlas for meningococcal disease [https://www.ecdc.europa.eu/en/meningococcal-disease/surveillanceand-disease-data/atlas].

85. Polkowska A, Toropainen M, Ollgren J, Lyytikäinen O, Nuorti JP. Bacterial meningitis in Finland, 1995-2014: a population-based observational study. BMJ Open. 2017;7(5):e015080.

86. Meningococcal disease [https://www.cdc.gov/meningococcal/index. html].

87. Rapport d'activite 2014 [https://www.pasteur.fr/fr/file/3273/download? token=8UaruHXt].

88. Active Bacterial Core Surveillance Report, Emerging Infections Program Network, Neisseria meningitidis, 2018 [https://www.cdc.gov/abcs/repor ts-findings/survreports/mening18.html].

89. Bodilsen J, Brandt CT, Sharew A, Dalager-Pedersen M, Benfield T, Schønheyder HC, Nielsen H. Early versus late diagnosis in communityacquired bacterial meningitis: a retrospective cohort study. Clin Microbiol Infect. 2018;24(2):166-70.

90. Wang B, Santoreneos R, Giles L, Haji Ali Afzali H, Marshall H. Case fatality rates of invasive meningococcal disease by serogroup and age: a systematic review and meta-analysis. Vaccine. 2019:37(21):2768-82.

91. Reese HE, Ronveaux O, Mwenda JM, Bita A, Cohen AL, Novak RT, Fox LM, Soeters HM. Invasive meningococcal disease in Africa's meningitis belt: more than just meningitis? J Infect Dis. 2019;220(220 Suppl 4):S263-5.

92. Taha MK, Presa J, Serra L. A review of the epidemiology of invasive meningococcal disease and vaccination strategies in North Africa. Int J Infect Dis. 2020;104:189-97.

93. Lahra MM, Enriquez RP, George CRR. Australian meningococcal surveillance programme annual report, 2017. Commun Dis Intell. 2018;2019:43

94. Fukusumi M, Kamiya H, Takahashi H, Kanai M, Hachisu Y, Saitoh T, Ohnishi M, Oishi K, Sunagawa T. National surveillance for meningococcal disease in Japan, 1999-2014. Vaccine. 2016:34(34):4068-71.

95. Pomar V, Benito N, López-Contreras J, Coll P, Gurguí M, Domingo P. Characteristics and outcome of spontaneous bacterial meningitis in patients with cancer compared to patients without cancer. Medicine (Baltimore). 2017;96(19):e6899.

96. Domingo P, Pomar V, Benito N, Coll P. The changing pattern of bacterial meningitis in adult patients at a large tertiary university hospital in Barcelona, Spain (1982-2010). J Infect. 2013;66(2):147-54.

97. Tuite AR, Kinlin LM, Kuster SP, Jamieson F, Kwong JC, McGeer A, Fisman DN. Respiratory virus infection and risk of invasive meningococcal disease in central Ontario, Canada. PloS One. 2010;5(11):e15493.

98. Muscat M, Spiteri G, Calleja N, Haider J, Gray SJ, Melillo JM, Mamo J, Cuschieri P. Invasive meningococcal disease in Malta: an epidemiological overview, 1994-2007. J Med Microbiol. 2009;58(Pt 11):1492-8.

99. Passmore E, Ferson MJ, Tobin S. EpiReview: meningococcal disease in NSW, 1991-2011: trends in relation to meningococcal C vaccination. N SW Public Health Bull. 2013;24(3):119-24.

100. Carville KS, Stevens K, Sohail A, Franklin LJ, Bond KA, Brahmi A, Romanes $F$, Ong KS. Increase in meningococcal serogroup W disease, Victoria, Australia, 2013-2015. Emerg Infect Dis. 2016;22(10):1785-7.

101. Centers for Disease Control and Prevention. Prevention: Notes from the field: serogroup C invasive meningococcal disease among men who have sex with men - New York City, 2010-2012. MMWR Morb Mortal Wkly Rep. 2013;61(51-52):1048.

102. Marcus U, Vogel U, Schubert A, Claus H, Baetzing-Feigenbaum J, Hellenbrand W, Wichmann O. A cluster of invasive meningococcal disease in young men who have sex with men in Berlin, October 2012 to May 2013. Euro Surveill. 2013;18(28):20523.

103. Martín-Sánchez M, Fairley CK, Bradshaw CS, Chen MY, Chow EPF. Meningococcal vaccine uptake among men who have sex with men in response to an invasive meningococcal C disease outbreak in Melbourne Australia. Sex Transm Infect. 2020;96(4):246-50.

104. Safadi MA, de Moraes J, Moraes C. A critical analysis of the epidemiologic profile of serogroup B meningococcal disease in Brazil, 2001-2015. 2021. https://espid2017.kenes.com/Documents/ESPID17\% 20abstracts.pdf. Accessed 25 Mar 2021. In., vol. 2021; 2017.

105. de TrzewikoswkiLima G, De Gaspari E. Study of the immune response in the elderly: is it necessary to develop a vaccine against Neisseria meningitidis for the aged? J Aging Res. 2019;2019:9287121.
106. van Kessel F, van den Ende C, Oordt-Speets AM, Kyaw MH. Outbreaks of meningococcal meningitis in non-African countries over the last 50 years: a systematic review. J Glob Health. 2019;9:1 010411.

107. Peterson ME, Li Y, Bita A, Moureau A, Nair H, Kyaw MH, Meningococcal Surveillance Group, Abad R, Bailey F, Garcia IF, et al. Meningococcal serogroups and surveillance: a systematic review and survey. J Glob Health. 2019:9(1):010409.

108. Cabrera-Gaytán DA, Pérez-Pérez GF, Arriaga-Nieto L, Vallejos-Parás A, Padilla-Velázquez R, Grajales-Muñiz C. Epidemiological surveillance of meningeal and encephalic syndrome in the Mexican social security Institute, 2012-2014. Rev Med Hosp Gen (Mex). 2017;80(3):130-8.

109. Mbaeyi SA, Blain A, Whaley MJ, Wang X, Cohn AC, MacNeil JR. Epidemiology of meningococcal disease outbreaks in the United States, 2009-2013. Clin Infect Dis. 2019:68(4):580-5.

110. Brueggemann AB, van JansenRensburg MJ, Shaw D, McCarthy ND, Jolley KA, Maiden MCJ, van der Linden MPG, Amin-Chowdhury Z, Bennett $D E$, Borrow $R$, et al. Changes in the incidence of invasive disease due to streptococcus pneumoniae, haemophilus influenzae, and Neisseria meningitidis during the COVID-19 pandemic in 26 countries and territories in the invasive respiratory infection surveillance initiative: a prospective analysis of surveillance data. Lancet Digit Health. 2021;3(6):e360-70.

111. Taha MK, Deghmane AE. Impact of COVID-19 pandemic and the lockdown on invasive meningococcal disease. BMC Res Notes. 2020;13(1):399.

112. Calendario vaccinale per la vita 2019 [https://www.vaccinarsi.org/notiz ie/2019/07/\%E2\%80\%8Bcalendario-vaccinale-per-la-vita-2019].

\section{Publisher's Note}

Springer Nature remains neutral with regard to jurisdictional claims in published maps and institutional affiliations.

Ready to submit your research? Choose BMC and benefit from

- fast, convenient online submission

- thorough peer review by experienced researchers in your field

- rapid publication on acceptance

- support for research data, including large and complex data types

- gold Open Access which fosters wider collaboration and increased citations

- maximum visibility for your research: over 100M website views per year

At BMC, research is always in progress.

Learn more biomedcentral.com/submissions 